\title{
O CONTEXTO SOCIAL DA APRENDIZAGEM DE GERENTES
}

THE SOCIAL CONTEXT OF MANAGERS' LEARNING

ANIELSON BARBOSA DA SILVA

Doutor em Engenharia de Produção pela Universidade Federal de Santa Catarina (UFSC). Mestre em Administração pela Universidade Federal da Paraíba (UFPB).

Professor adjunto I do Departamento de Administração da Universidade Federal da Paraíba (UFPB). Campus Universitário I, Conjunto Castelo Branco,

Cidade Universitária - João Pessoa - PB

CEP 58059-900

E-mail: anielson@pq.cnpq.br 


\section{RESUMO}

O artigo tem como objetivo analisar a influência do contexto social na aprendizagem gerencial. Existem várias abordagens teóricas para compreender como os gerentes aprendem, e no artigo discutem-se algumas dessas perspectivas, focalizando uma perspectiva interacionista que destaca a interação com o ambiente e o contexto como mediadores do processo de aprendizagem. A aprendizagem gerencial é uma abordagem que surgiu para suprir um gap entre a teoria e a prática da educação e do desenvolvimento gerencial. Existem evidências de que a aprendizagem não é apenas um fenômeno individual, mas coletivo, e que ocorre em um contexto de participação social. Conclui-se que os programas de aprendizagem gerencial devem buscar compatibilizar o desenvolvimento de conhecimentos técnicos vinculados à educação com o desenvolvimento de habilidades gerenciais e a mudança nas perspectivas de significados, por meio da vivência de experiências em situações ricas em aprendizagem, revelando o seu caráter transformador e emancipatório.

\section{PALAVRAS-CHAVE}

Contexto social; Gerente; Aprendizagem; Experiência; Reflexão.

\section{ABSTRACT}

The article aims to analyze the influence from social context in learning management. There are many theoretical approaches to understand how managers learn, and in this article it's discussed, focusing on the interactionist perspective, which highlights the interaction with the environment and context as mediators of the learning process. The management learning is an approach that emerged to fill a gap between theory and practice of management education and development. There are evidences of that learning is not only an individual phenomenon, but collective and that occurs in a context of social participation. It was concluded 
that the management learning programs should seek reconciling the expertise development related to education with the skills management development and meaning prospective change, from the lived experience in learning rich situations, revealing emancipatory and transformer character from learning.

\section{KEYWORDS}

Social context; Manager; Learning; Experience; Reflection.

\section{CONSIDERAÇÕES INICIAIS}

A aprendizagem é um processo multifacetado que depende de uma série de variáveis contextuais que influenciam a maneira como as pessoas vêem o mundo e atribuem significados a determinados eventos. Para Cranton (i994, p. 48), "a aprendizagem é multidimensional e pode influenciar as perspectivas de significado de várias maneiras e em diferentes níveis".

O processo de aprendizagem de gerentes é multidimensional porque abrange uma dimensão objetiva e uma subjetiva da prática gerencial. Na dimensão objetiva, a aprendizagem ocorre por meio de ações formais, voltadas para a formação técnico-profissional e para a aquisição de conhecimentos e competências técnicas, sobretudo vinculadas a procedimentos e técnicas para a formulação e implementação de estratégias (produção, marketing, finanças, recursos humanos), orientações para a prática gerencial, além de contribuir para a reflexão e para o desenvolvimento de uma visão sistêmica, trabalho em equipe, negociação, técnicas para a tomada de decisões, entre outros. Além disso, no contexto da ação gerencial, existe uma série de atividades que favorecem a aprendizagem, tais como os relacionamentos com pares, superiores e subordinados, a leitura de manuais de normas, procedimentos, sistemas de informações gerenciais, entre outros. Há também uma dimensão subjetiva, interior a cada pessoa, que a torna singular e que também contribui para a aprendizagem. A busca do autoconhecimento, o processo de reflexão sobre as experiências vividas, as sensações, o medo, os traumas pessoais, o sofrimento não são abordados com muita freqüência no discurso gerencial. A lógica do sucesso profissional, no contexto empresarial na atualidade, muitas vezes cria um protótipo de profissional e o envolve em torno de uma representação social que o leva a não demonstrar a singularidade e a individualidade do ser humano, do ser pessoa.

Os valores e as atitudes das pessoas são incorporados à ação, ao longo da vida, e por isso não podemos conceber que um gerente que almeja ser bem-suce- 
dido no campo profissional valorize apenas a dimensão objetiva inerente à sua aprendizagem e à sua própria vida. A dimensão subjetiva é determinante, pois é ela que vai ajudá-lo em seu desenvolvimento pessoal e contribuir para o desenvolvimento de competências em ação.

Uma competência em ação envolve um conjunto de atributos profissionais e pessoais que ajudam o gerente a lidar com eventos, tais como resolver problemas, implementar um processo de mudança, formular uma estratégia, criar um ambiente propício para o desenvolvimento dos colaboradores em um contexto profissional. Para o desenvolvimento de uma competência, o gerente não precisa apenas de conhecimento, mas de experiência. A experiência não envolve apenas situações vividas no contexto profissional, mas no espaço total da vida, e isso inclui as experiências vividas na escola, na família, nos relacionamentos sociais, afetivos e profissionais.

Essas considerações revelam que o processo de aprendizagem gerencial é multifacetado e complexo. A análise de como os gerentes aprendem, sob esse olhar, ganha destaque, e as perspectivas de aprendizagem social podem contribuir para ampliar o nível de compreensão sobre o contexto e os fatores que influenciam a aprendizagem de gerentes.

Este artigo tem como objetivo analisar a influência do contexto social na aprendizagem de gerentes. Num primeiro momento, discutem-se alguns fatores contextuais que influenciam a aprendizagem gerencial; em seguida, apresentamse algumas perspectivas teóricas da aprendizagem de adultos, além de abordar o significado da aprendizagem gerencial; e finalmente, ressalta-se a influência do contexto social na aprendizagem gerencial.

\section{FATORES CONTEXTUAIS QUE INFLUENCIAM A APRENDIZAGEM DE ADULTOS}

O contexto é um produto social e histórico produzido junto com as atividades que ele apóia: agentes, objetos, atividades, artefatos materiais e simbólicos que constituem um sistema heterogêneo que evolui ao longo do tempo (GHERARDI; NICOLINI; ODELLA, I998b) e que sofre a influência de fatores demográficos, econômicos, tecnológicos e culturais, os quais estão interligados e são dimensões que afetam a aprendizagem de gerentes.

A demografia é uma variável interveniente porque as mudanças na sociedade implicam a necessidade de as pessoas aprenderem para adaptar-se: "A composição de uma sociedade é um fator importante na provisão de oportunidades de aprendizagem para cidadãos de todas as idades" (MERRIAN; CAFFARELLA, I99I, p. IO). 
A economia é outro fator determinante, porque a velocidade da mudança gera a necessidade da aprendizagem. Os mercados buscam competitividade, e apenas aqueles que estiverem aptos a competir terão condições de evoluir. A era da informação e do conhecimento promoveu transformações nas organizações e nos trabalhadores, que passaram a valorizar o conhecimento como insumo para a geração de valor. Fatores econômicos estão moldando a natureza da nossa sociedade e, por extensão, a natureza da aprendizagem gerencial. A economia global, a busca de uma sociedade da informação e dos serviços, e as mudanças na configuração da força de trabalho são essenciais para avaliar o processo de aprendizagem e os agentes que participam dele (MERRIAM; CAFFARELLA, I99I).

A tecnologia inclui o conhecimento, as ferramentas, as técnicas e as atividades usadas para transformar insumos em resultados. Tecnologia inclui maquinário, habilidades e procedimentos de trabalho (DAFT, 2003). Com as transformações ocorridas no ambiente, as tecnologias se tornam obsoletas mais rapidamente, $\mathrm{o}$ que influencia a aprendizagem. A era da informação e do conhecimento, aliada à tecnologia da informação, provocou mudanças na estrutura da sociedade e na aprendizagem. A tecnologia afeta consideravelmente o conhecimento que se torna obsoleto rapidamente em conseqüência da acelerada taxa de mudança (STEWART, I998). De acordo com Merriam e Caffarella (I99I), metade do que a maioria dos profissionais aprende quando conclui seus treinamentos formais torna-se obsoleta em menos de cinco anos. Assim, a necessidade da educação continuada tem aumentado no apoio à geração e difusão do conhecimento.

Além dos fatores citados, considera-se a cultura uma outra dimensão que interfere na aprendizagem, pois determina a maneira como as pessoas agem dentro de um determinado sistema social. É formada por um sistema de crenças, valores e atitudes que servem como balizadores do comportamento humano. A cultura pode interferir no processo de aprendizagem, na medida em que as pessoas muitas vezes relutam em sair da zona de conforto e abandonar seus modelos mentais. Os modelos mentais "são pressupostos profundamente arraigados, generalizações ou mesmo imagens que influenciam nossa forma de ver o mundo e de agir" (SENGE, I999, p. 42).

Segundo Gold (I995, p. 20),

o aprendizado envolve mudanças, e estas, quaisquer que sejam e em qualquer situação, nem sempre são confortáveis [...] as mudanças podem, com freqüência, fazer que o desempenho piore antes de melhorar, e este risco pode ser demasiado grande.

A diversidade cultural e as mudanças nas relações entre os países, por exemplo, reforçaram a importância da aprendizagem como um pré-requisito para a 
adaptação. As dimensões mencionadas anteriormente não atuam isoladamente. Todo o sistema está conectado e qualquer mudança em uma delas provoca mudanças nas demais.

\section{PERSPECTIVAS TEÓRICAS DA APRENDIZAGEM}

Existem várias perspectivas de aprendizagem que norteiam o desenvolvimento e a educação de adultos. As contribuições da psicologia, da antropologia e da sociologia foram fundamentais para a evolução dos estudos direcionados para avaliar como os adultos aprendem. O debate em torno do processo de aprendizagem gerencial tem como ponto de partida a educação de adultos para ilustrar que a compreensão do significado e do processo de aprendizagem pode ser orientada por várias linhas de pensamento.

Merriam e Caffarela (I99I, p. I2I-I39) discutem o processo de aprendizagem de adultos e o definem como parte de um quebra-cabeça. As autoras afirmam que, apesar de existirem várias maneiras de definir a aprendizagem, a maioria delas inclui os conceitos de mudança de comportamento e experiência. As principais perspectivas teóricas norteadoras da aprendizagem são: a behaviorista, a cognitiva, a humanista, a social e a transformadora.

$\mathrm{Na}$ perspectiva behaviorista, a aprendizagem é manifestada por uma mudança no comportamento, e a aprendizagem das pessoas é determinada por elementos do ambiente e não do aprendiz individualmente. Em contrapartida, a perspectiva cognitiva coloca o ser humano como agente ativo no processo de aprendizagem, que interpreta sensações e dá significados aos eventos que afetam a sua consciência. O aprendiz pensa sobre todos os ingredientes necessários para resolver um problema e agrupá-lo, de maneira cognitiva, de uma forma ou de outra até encontrar uma solução (MERRIAM; CAFFARELA, I99I). O que diferencia essas duas correntes é que, para os behavioristas, o locus da aprendizagem está no ambiente, e, para os cognitivistas, nos processos mentais controlados pelo indivíduo.

Na perspectiva humanista, a aprendizagem é função da motivação e envolve responsabilidades. As pessoas aprendem porque almejam o crescimento. Os humanistas se recusam a aceitar o predeterminado pelo comportamento ou pelo subconsciente de alguém. Nesse sentido, o ser humano exerce o controle sobre o seu destino, possui um potencial ilimitado para o crescimento e o desenvolvimento, tem a liberdade de agir e o seu comportamento é conseqüência de escolhas.

Outra perspectiva da aprendizagem é a social, que considera a aprendizagem pessoal conseqüência de um processo de observação de outras pessoas. 
Para Merriam e Cafarella (I99I, p. I39), o foco da aprendizagem social é o cenário em que ela ocorre. "A aprendizagem ocorre por meio da observação das pessoas em um ambiente específico. Além disso, a aprendizagem é uma função da interação entre pessoa, ambiente e comportamento".

Cranton (I994, p. 3-2I) abordou as diversas perspectivas da aprendizagem seguindo uma orientação paradigmática. A autora inicia a discussão levantando um questionamento sobre a possibilidade de estabelecer características genéricas para a aprendizagem de adultos. Após fazer uma análise de vários pesquisadores, como Knowles, Mezirow e Kolb, Cranton (I994) estabelece algumas dessas características, afirmando que a aprendizagem de adultos é freqüentemente vista como voluntária, autodirigida, prática, participativa ou colaborativa. Além disso, a aprendizagem envolve partilhar experiências e recursos, provoca ansiedade e pode ser limitada quando os indivíduos subestimam suas habilidades.

As perspectivas de aprendizagem, segundo Cranton (I994), são vinculadas a dois paradigmas: o positivista e o construtivista. O positivista é mais facilmente compreendido por meio do pensamento científico ou do conhecimento instrumental, que são decorrentes de leis e dados empíricos. A aprendizagem é considerada o processo de acúmulo de informação. O behaviorismo e as teorias cognitivas de aprendizagem centradas no processamento da informação são enquadrados nesse paradigma. No paradigma construtivista, o conhecimento é construído pelo indivíduo, que percebe o mundo em uma realidade que não é objetiva. A aprendizagem é um processo de construir significados e transformar as compreensões. As teorias humanística e contextual (social) da aprendizagem se enquadram nesse paradigma.

Outro autor que pode ser utilizado como base para classificar as teorias de aprendizagem foi Habermas (apud CRANTON, I994, p. 9), que propôs três domínios de conhecimento:

a) o conhecimento técnico contempla a informação sobre relacionamentos de causa e efeito no ambiente;

b) o conhecimento prático preocupa-se com a compreensão dos significados dos outros e envolve normas sociais, valores e conceitos políticos;

c) o conhecimento emancipatório é adquirido por meio da auto-reflexão crítica.

Com base nas idéias de Habermas, Mezirow (I99I apud TAYLOR, I998, p. 5-I3) desenvolveu a teoria da aprendizagem transformadora, considerada uma teoria de aprendizagem adulta, abstrata, idealizada e calcada na natureza da comunicação humana. Lucena (200I, p. 30), ao analisar a definição proposta por Mezirow sobre a aprendizagem, considera que está fundamentada nos pressu- 
postos construtivistas e embasada na "idéia de que os adultos constroem significados a partir das experiências vivenciadas e que as ações humanas em relação às coisas baseiam-se no significado que as coisas possuem para as pessoas".

O processo de aprendizagem ocorre a partir do momento em que uma experiência vivenciada por uma pessoa a leva a fazer associações com seus pressupostos, crenças, valores e conhecimentos, que formam um quadro de referências. Após um processo de interpretação, a pessoa age com base na associação entre a experiência vivida em determinada situação e o seu quadro de referências. Lucena (200I, p. 30) considera a ação a

implementação criativa de um propósito e pode envolver uma tomada de decisão, criação de uma associação, revisão de um ponto de vista, reestruturação da solução de um problema, modificação de uma atitude ou produção de uma mudança de comportamento.

A aprendizagem transformadora tenta explicar como nossas expectativas, estruturadas em suposições e pressuposições, diretamente influenciam o significado que obtemos de nossas experiências. Trata-se da revisão de estruturas de significados das experiências, que é adicionada pela teoria da perspectiva transformadora (TAYLOR, I998).

Para Silva, Cunha e Possamai (200I, p. I3), a teoria da aprendizagem transformadora proposta por Jack Mezirow procura demonstrar que "o aprendizado transforma o conhecimento existente em nova perspectiva e provoca a emancipação do aprendiz".

Neste artigo, as discussões sobre essas perspectivas teóricas da aprendizagem não serão aprofundadas, mas considera-se que conhecê-las pode auxiliar os gerentes e demais profissionais a ampliar o escopo de análise sobre os processos de aprendizagem no ambiente profissional e na vida pessoal.

Compreender o processo de aprendizagem de gerentes numa perspectiva multidimensional implica "um olhar" que perpassa fronteiras ou espaços sociais da vida das pessoas, tornando essa compreensão complexa e necessária em razão das transformações ocorridas no ambiente e na prática gerencial. Antes de abordar a influência do contexto social na aprendizagem de gerentes, torna-se necessário compreender o significado da aprendizagem gerencial. 


\section{SIGNIFICADO DA APRENDIZAGEM GERENCIAL}

A aprendizagem gerencial emergiu para suprir um gap entre a teoria e a prática da educação gerencial e do desenvolvimento gerencial; começou a ser aplicada pela teoria da aprendizagem, pela psicologia, pela pesquisa educacional e pela sociologia nos processos pelos quais os gerentes aprendiam na ação ou em salas de treinamento de escolas de negócios, contribuindo para essas disciplinas de "origem", mas também para o gerenciamento e a teoria da organização (FOX, I997).

Fox (1997, p. 34-35) define a aprendizagem gerencial como

o estudo do gerenciamento dos processos de aprendizagem, especialmente aqueles que contribuem para a prática do gerenciamento, incluindo a educação e o desenvolvimento gerenciais.

A aprendizagem gerencial é o estudo da aprendizagem do gerenciamento e do gerenciamento da aprendizagem (FOX, I994).

A aprendizagem do gerenciamento tem como objetivo desenvolver competências gerenciais (conhecimentos, habilidades, valores morais) por meio de atividades de educação e desenvolvimento. Já o gerenciamento da aprendizagem é um processo que ocorre na prática gerencial, por meio da vivência de experiências no trabalho e na vida pessoal.

Ao concluírem um estudo sobre os processos de aprendizagem de gerentes, Tamkin e Barber (I998) também chegaram à conclusão de que a aprendizagem de gerentes envolve treinamento por meio da educação e desenvolvimento pessoal, e que os resultados da aprendizagem incluem mudanças nas habilidades, no conhecimento, na compreensão e nos insights. O processo de aprendizagem atua em um contínuo do treinamento por meio da educação até o desenvolvimento. O Quadro I procura ilustrar alguns exemplos do que os gerentes aprenderam, levando em consideração cinco categorias. 
QUADRO I

\section{CINCO CATEGORIAS DA APRENDIZAGEM}

\begin{tabular}{|c|c|}
\hline $\begin{array}{l}\text { CATEGORIA } \\
\text { (O QUE APRENDEU?) }\end{array}$ & EXEMPLOS \\
\hline $\begin{array}{l}\text { Conhecimento } \\
\text { técnico }\end{array}$ & $\begin{array}{l}\text { - Aquisição de conhecimentos ou habilidades com base em eventos de } \\
\text { aprendizagem (cursos ou eventos informais no trabalho), tais como } \\
\text { habilidades associadas ao uso do computador ou de negociação. }\end{array}$ \\
\hline $\begin{array}{l}\text { Habilidades } \\
\text { gerenciais }\end{array}$ & $\begin{array}{l}\text { - Compreensão das necessidades das pessoas. } \\
\text { - Compreensão da influência da vida pessoal no trabalho das pessoas. } \\
\text { - Habilidade de trabalhar com as pessoas de várias áreas da organização. } \\
\text { - Feedback das pessoas em relação ao seu estilo de gestão. }\end{array}$ \\
\hline $\begin{array}{l}\text { Compreensão da } \\
\text { organização }\end{array}$ & $\begin{array}{l}\text { - Visão integrada da organização. } \\
\text { - Visão sistêmica dos negócios da organização, da cultura e de } \\
\text { abordagens sobre o trabalho e a vida organizacional. }\end{array}$ \\
\hline $\begin{array}{l}\text { Compreensão do } \\
\text { impacto nos outros }\end{array}$ & $\begin{array}{l}\text { - Compreensão de impacto de seu trabalho nas outras pessoas, nos } \\
\text { pares e nos subordinados. } \\
\text { - Melhoria em seu networking. } \\
\text { - Desenvolvimento de um estilo de gestão mais participativo, ampliando } \\
\text { o espaço dos subordinados. } \\
\text { - Busca de apoio das pessoas na implantação de mudanças. } \\
\text { - Compreensão da necessidade de compartilhar suas visões, sem impor o } \\
\text { seu posicionamento. }\end{array}$ \\
\hline Compreensão de si & $\begin{array}{l}\text { - Habilidades pessoais (aceitar feedback e de forma construtiva). } \\
\text { - Reflexão sobre o estágio na carreira sob uma perspectiva de equilíbrio } \\
\text { entre o trabalho e a vida. } \\
\text { - Compreensão de seus próprios processos de pensamento (por } \\
\text { exemplo, suspender o seu julgamento em relação aos outros até obter } \\
\text { mais informação). } \\
\text { - Compreensão de seu estilo pessoal para ser mais efetivo no trabalho. }\end{array}$ \\
\hline
\end{tabular}

Fonte: Elaborado com base em Tamkin e Barber (I998, p. 34-39).

O Quadro I destaca que o processo de aprendizagem envolve o desenvolvimento de conhecimentos, habilidades e atitudes, de natureza técnica, humana e conceitual, além de um maior conhecimento de si. Os resultados da pesquisa podem servir de base para ampliar a visão sobre o desenvolvimento de gerentes, principalmente na elaboração de programas voltados para a aprendizagem gerencial.

Fox (I997) aborda a relação entre a educação e o desenvolvimento gerencial, que são sobrepostos, mas também distintos em alguns aspectos, como demonstra o Quadro 2. 


\section{QUADRO 2}

\section{DIFERENÇAS ENTRE DESENVOLVIMENTO}

GERENCIAL E EDUCAÇÃO GERENCIAL

\begin{tabular}{|c|c|c|}
\hline ASPECTOS & DESENVOLVIMENTO GERENCIAL & EDUCAÇÃO GERENCIAL \\
\hline Foco & Prática - saber como fazer. & Teoria - saber o que e por quê. \\
\hline Conteúdo & $\begin{array}{l}\text { Desenvolve os conhecimentos } \\
\text { pessoais, os repertórios e } \\
\text { habilidades (por exemplo, gestão } \\
\text { do tempo, estresse gerencial, } \\
\text { assertividade, trabalho em equipe, } \\
\text { negociação, entre outros). }\end{array}$ & $\begin{array}{l}\text { Desenvolve habilidades críticas e } \\
\text { analíticas nas disciplinas relevantes para } \\
\text { a administração (por exemplo, economia, } \\
\text { gestão das operações e pesquisa, } \\
\text { contabilidade, finanças, marketing, teoria } \\
\text { das organizações, comportamento, } \\
\text { estratégia). }\end{array}$ \\
\hline $\begin{array}{l}\text { Métodos de } \\
\text { ensino }\end{array}$ & $\begin{array}{l}\text { Usa uma série de métodos } \\
\text { focados na ação. }\end{array}$ & $\begin{array}{l}\text { Derivada de métodos tradicionais (por } \\
\text { exemplo, leitura, seminários). }\end{array}$ \\
\hline Organização & Mecanismos de mercado. & Sistema educacional. \\
\hline
\end{tabular}

Fonte: Elaborado com base em Fox (I997, p. 2I).

O grande desafio dos programas de aprendizagem gerencial é compatibilizar a educação e o desenvolvimento do gerente, de modo que este possa desenvolver as competências necessárias para enfrentar os desafios que encontra em sua prática profissional. Na Figura I, apresenta-se o escopo do estudo da aprendizagem gerencial, ratificando o seu nível de complexidade e a sua abrangência no processo de formação e desenvolvimento gerencial.

\section{FIGURA I}

\section{ESCOPO DA APRENDIZAGEM GERENCIAL}

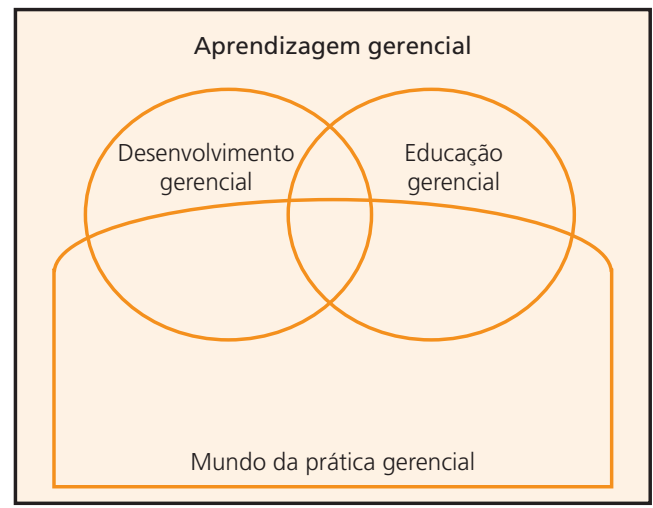

Fonte: Fox (1997, p. 23). 
A discussão em torno da relação entre educação e aprendizagem nos programas que fomentam a aprendizagem de gerentes nas organizações deve considerar que a educação não leva necessariamente à aprendizagem e que esta não está necessariamente conectada com a educação. Para que a aprendizagem ocorra no ambiente de trabalho, torna-se necessário que haja uma troca entre o indivíduo e a situação de trabalho (PAULSSON; SUNDIN, 2000). Existem, segundo Paulsson e Sundin (2000), alguns fatores relevantes para que o processo de aprendizagem ocorra:

- $\quad$ a participação dos colegas de trabalho na formulação de metas, planejamento e desenvolvimento de atividades;

- $\quad$ tarefas com um elevado potencial de aprendizagem;

- informação e um conhecimento teórico aprofundado;

- experimentos locais para testar diferentes alternativas de ação;

- troca de experiência e reflexão;

- processos de grupo, cultura e estrutura organizacional com apoio da aprendizagem;

- apoio, mas também uma pressão para a mudança e a legitimação da administração em diferentes níveis da organização.

Esses aspectos indicam que os programas voltados para a aprendizagem gerencial devem considerar que os processos de aprendizagem ocorrem também por meio de relacionamentos, da natureza do trabalho a ser desenvolvido, da troca de experiências, da capacidade de reflexão, além de um modelo de gestão que favoreça a ocorrência da aprendizagem. Isso indica que um programa de aprendizagem gerencial no contexto da organização não abrange apenas a realização de cursos e seminários, mas depende da delimitação de um contexto social que incentive a aprendizagem. Se o gerente participar de um curso e não conseguir aplicar o que foi abordado no contexto da organização, o processo de aprendizagem é comprometido. O gerente deve encarar a aprendizagem como dinâmica e contextualizada ao ambiente da sua prática. Compatibilizar educação, desenvolvimento de competências e prática gerencial contribui para um efetivo processo de aprendizagem gerencial.

A base para a competência profissional futura está na capacidade de aprender a como aprender, o que requer o desenvolvimento de uma teoria própria da prática em condições de tempo reais. Isso significa que o profissional deve aprender a desenvolver microteorias de ação que, quando estruturadas em um padrão, representam uma teoria efetiva de prática. O profissional deve ser capaz de agir de acordo com suas microteorias de ação e refletir sobre suas ações, relacionando-as às variáveis implícitas que governam seu comportamento e deter- 
minam o impacto do seu comportamento no comportamento do mundo, na aprendizagem e na efetividade (ARGYRIS; SCHON, I974). Os autores consideram dois tipos de comportamentos relacionados com a aprendizagem: o singleloop e o double-loop. Na aprendizagem em single-loop, os indivíduos aprendem novas técnicas para eliminar conflitos e para manter uma constância no desenho de ações que satisfaçam as variáveis governantes. Já na aprendizagem em double-loop, as pessoas aprendem a lidar com o processo de resolução de conflitos, em vez de eliminá-los, e a mudar as variáveis que governam os cenários. O impacto na aprendizagem envolve especialmente a aprendizagem em double-loop (ARGYRIS; SCHON, I974).

$\mathrm{Na}$ prática gerencial do comportamento de aprendizagem em single-loop, o gerente busca resolver um problema visando evitar o surgimento de conflitos e manter o curso de suas ações diárias. A estabilidade e a manutenção do status quo são aspectos relevantes para a atuação do gerente. O comportamento que predomina na prática gerencial é o focado nas tarefas. Já na aprendizagem em doubleloop, existe a capacidade de reflexão, a necessidade de buscar novas alternativas para gerenciar os conflitos e também lidar com as contingências de forma mais proativa, estimulando a criatividade. A mudança é um processo natural da prática gerencial, e a reflexão na ação passa a ser determinante no desenvolvimento individual e da equipe de trabalho. O comportamento que predomina na prática de gerentes que valorizam e difundem a aprendizagem em double-loop é mais voltado para as relações e para a mudança (cf. YUKL, I998).

Os aspectos determinantes para a implantação de um programa de aprendizagem gerencial envolvem a tríade educação, desenvolvimento e prática gerencial que incentivem a reflexão na ação. Ao avaliar sua trajetória profissional, um gerente percebe que as experiências mais significativas e ricas em aprendizagem foram aquelas em que houve a troca de experiências, em que os comportamentos vivenciados o levaram a ter sensações que marcaram a sua vida e que hoje servem de referência para as suas ações. Quanto mais reflexiva e focada na ação for a prática gerencial, maior será a capacidade de potencializar o desenvolvimento e a aprendizagem.

O conceito de reflexão na ação foi proposto por Schon $(1983,2000)$ para ajudar as pessoas a lidarem com o conhecimento que muitas vezes é tácito e difícil de ser estruturado:

Às vezes, através da observação e da reflexão sobre nossas ações, fazemos uma descrição do saber tácito que está implícito nelas. Nossas descrições serão de diferentes tipos, dependendo de nossos propósitos e das linguagens disponíveis para essas descrições (SCHON, 2000, p. 3I). 
A reflexão na ação, para o autor, é um processo que envolve uma reflexão sobre as ações, tentando descobrir como o ato de conhecer-na-ação contribuiu para um determinado resultado inesperado. Um prático pode refletir sobre as normas tácitas e apreciações que são a base do julgamento, ou sobre as estratégias e teorias implícitas nos padrões de comportamento. Ele pode refletir sobre os sentimentos em uma situação que o levou a adotar um direcionamento específico para a ação, ou sobre a maneira utilizada para estruturar um problema que tentou resolver, ou ainda sobre o papel construído por ele dentro de um contexto institucional mais amplo (SCHON, I983).

No seu estudo com gerentes, Tamkin e Barber (1998, p. 26-30) abordam como os gerentes aprendem. Os autores afirmam que os gerentes aprendem de uma ampla variedade de experiências e oportunidades. Quando questionados em relação às suas percepções de como têm aprendido, freqüentemente mencionam experiências associadas ao desenvolvimento formal, mas também outras experiências menos formais, como aprender com os outros, as experiências de trabalho e a reflexão.

A reflexão ajuda o gerente a demonstrar uma maior consciência da apreciação da experiência da aprendizagem. Para alguns gerentes, não houve uma mera articulação da experiência da aprendizagem, mas também uma atenção interna deliberada para ela e uma integração da experiência em si mesma, que envolve ações do tipo aprender fazendo, errando (TAMKIN; BARBER, I998, p. 29). Isso revela os vínculos entre as experiências de aprendizagem e o contexto da ação profissional.

\section{O papel do contexto social na APRENDIZAGEM DE GERENTES}

A perspectiva da aprendizagem social considera que a aprendizagem ocorre por meio da observação das pessoas em um determinado contexto. Os processos de aprendizagem são intrinsecamente sociais e também um fenômeno coletivo (BROWN; DUGUID, 200I). Não se pode negar a integridade dos indivíduos, mas é preciso destacar que o que o gerente aprende reflete o contexto social, e isso refletirá na aplicabilidade prática do que foi aprendido:

A aprendizagem ocorre dentro de um contexto de participação (social), e não na mente individual. Isso significa que as diferenças em perspectiva (as perspectivas múltiplas) entre os co-participantes são instrumentais na geração da aprendizagem (ELKJAER, 200I, p. I08). 
Gherardi e Nicolini (200I) destacam que o conceito de participação possibilita a aprendizagem organizacional que ocorre em ação e por meio da ação e que a aprendizagem social envolve uma rede de comportamentos coletivos baseada na difusão do conhecimento.

Alguns estudos sobre a aprendizagem gerencial foram desenvolvidos tendo como base o contexto social. Gherardi, Nicolini e Odella (I998b) desenvolveram uma pesquisa com o objetivo de explorar as várias maneiras pelas quais a experiência prática e as habilidades tácitas são passadas dos trabalhadores seniores para os novatos, e identificar o processo pelo qual o novo conhecimento é assimilado em uma comunidade de prática.

As autoras afirmam que os estudos envolvendo a aprendizagem organizacional estão passando por uma revolução. Destacam a visão clássica da aprendizagem, na qual o aprendiz é um ator individual que processa a informação e modifica suas estruturas mentais, e propõem uma visão centrada em Bruner e Haste, na qual o aprendiz é um ser humano que constrói sua compreensão e aprende de interações sociais dentro de cenários socioculturais (GHERARDI, NICOLINI; ODELLA, I998b).

Essa visão coloca o contexto social no epicentro do processo de aprendizagem. Nessa perspectiva, pode-se afirmar que a "aprendizagem é socialmente construída nas organizações para transformar a cognição adquirida em ação para ser responsável pelo conhecimento abstrato" (NICOLINI; MEZNAR, I995). A aplicação de uma perspectiva desloca o processo de informação e modificação da estrutura cognitiva para o processo de participação e interação que fornece um contexto próprio para a aprendizagem (GHERARDI; NICOLINI; ODELLA, I998b).

$\mathrm{O}$ ato de apreender significados, que resulta em aprendizagem, é o resultado da ação de todas as pessoas que atuam no sistema. Para que a aprendizagem seja efetiva e possa promover a geração de conhecimento, a organização deve desenvolver um sistema de relações sociais que possibilite a todos os seus integrantes uma participação ativa e legítima, capaz de transformar a realidade por meio da ação (NICOLINI; MEZNAR, I995).

Uma ação transformadora, na visão de Freire (I987, p. 92), ocorre quando o homem passa a ser responsável pela criação da sua história: "Não é no silêncio que os homens se fazem, mas na palavra, no trabalho, na ação-reflexão".

Ao diferenciar o homem dos animais, Giddens (I978, p. 107) destaca a incapacidade de adaptação dos sujeitos ao mundo material, o que os leva a interagir com o seu meio ambiente para dominá-lo e não simplesmente ajustar-se a ele como se fosse algo já estabelecido: "Assim, os seres humanos se modificam ao modificar o mundo que os envolve, num processo contínuo e recíproco”. 
A aprendizagem, no todo, envolve a aquisição de identidades que refletem como o aprendiz vê o mundo e como o mundo vê o aprendiz. Aprender o mais simples trabalho é, então, um processo social complexo que não pode ser capturado na noção de que toda a aprendizagem ocorre na cabeça dos indivíduos (BROWN; DUGUID, 200I).

Lave e Wenger (I99I) consideram que a aprendizagem ocorre no contexto da prática social. É um contexto específico que envolve uma coletividade de pessoas, e por isso a aprendizagem é situada. Os autores consideram que a aprendizagem decorre de um processo de participação periférica legitimada. Esse processo também está vinculado a vários contextos de socialização, tais como o regulatório (autoridade e a ordem moral), o educacional (desenvolvimento de habilidades e da expertise), o inovador ou imaginário (auto-imagem, identidade individual e coletiva produzidas por meio da experimentação e negociação) e o interpessoal (socialização e apropriação de relacionamentos sociais que tornam a pessoa membro de uma comunidade) que podem facilitar ou dificultar a aprendizagem (GHERARDI; NICOLINI, 200I).

Em um programa de trainee, por exemplo, uma pessoa é colocada na posição de aprendiz de gerente e só passará a ter acesso a todo o conhecimento do grupo se for legitimada por todos os integrantes do contexto social em que atua. O domínio de todo o conhecimento depende da compreensão e do aumento no nível de complexidade no desenvolvimento de seu trabalho. À medida que o grupo passa a aceitar o trainne como integrante ativo e legítimo, este passa a incorporar todo o conhecimento, sobretudo o conhecimento tácito. Caso não seja legitimado, ou seja parcialmente legitimado, não terá acesso a todas as fontes para a compreensão de significados e seu envolvimento com o grupo e sua aprendizagem passam a ser prejudicados: "A forma como a legitimação ocorre é uma característica definidora da maneira de pertencer" (LAVE; WENGER, I99I, p. 35) a um contexto social. Vale ressaltar que a participação é um elemento constitutivo do conteúdo da aprendizagem. Assim, quando ocorre a legitimação pelo grupo, o nível de aquisição de conhecimento e compreensão da prática gerencial é ampliado, o que contribui para um maior entendimento sobre o gerenciamento da aprendizagem.

A aprendizagem gerencial, sob essa perspectiva, é um processo que envolve várias etapas. O bom desempenho do gerente após ingressar em uma organização está vinculado a sua legitimação como membro do grupo. Com base em pesquisas, Gherardi, Nicolini e Odella (I998b) categorizaram quatro estágios por que passa um aprendiz em uma empresa.

- Novato: aplica regras de um contexto independente (aplicação do conhecimento aprendido na escola; segue as instruções de manuais). 
- Iniciante avançado: realiza experiências práticas na aprendizagem para reconhecer os elementos situacionais que dependem do contexto e não são especificados por regras de um contexto independente.

- Aprendiz competente: sabe como escolher ou organizar um plano pelo uso simultâneo do contexto independente e as regras do limite do contexto, não respeitando as regras se a situação justifica ou explora sua incompletude.

- Aprendiz expert e habilidoso: caracteriza-se pelo envolvimento, pela rapidez, fluidez e intuição. As regras que orientam a performance de uma atividade particular podem ser esquecidas porque estão taken for granted, tornam-se hábitos, parte de um esquema corporal, da inconsciência.

Todo o conhecimento que vai sendo adquirido durante o processo e que reside no ambiente organizacional depende de socialização e legitimação. Nesse processo, dois conceitos são fundamentais: o de comunidade de prática e o de participação periférica legitimada.

O conceito de comunidade de prática foi proposto por Lave e Wenger (I99I) e utilizado por vários autores como Brown e Duguid (200I); Gherardi, Nicolini e Odella (I998b); Elkjaer (200I) entre outros.

Gherardi (2000) ressalta que o conhecimento organizacional como um fenômeno social e coletivo pode ser baseado na noção de prática e na idéia de comunidade de prática, um constructo conceitualizado por vários autores como um agregado informal definido não apenas por seus membros, mas também pela forma compartilhada como as pessoas realizam seus trabalhos e interpretam eventos.

Uma comunidade de prática não é uma maneira de postular a existência de um novo grupo informal ou sistema social dentro de uma organização, mas é uma maneira de enfatizar que toda prática é dependente de um processo social pelo qual ela é sustentada e perpetuada e que a aprendizagem ocorre por meio do engajamento naquela prática (GHERARDI, NICOLINI, ODELLA, I998a).

Lucena (200I, p. 45) alerta que "o termo comunidade não implica a existência de um grupo bem definido e identificável, mas que determinadas pessoas compartilham alguns entendimentos sobre o que fazem".

Em comunidades de prática, são estabelecidas relações ao redor das atividades, que por sua vez, tomam forma por meio de relações sociais e das experiências daqueles que as realizam com o objetivo de tornar o conhecimento e a habilidade parte da identidade do indivíduo, com o propósito de que este seja inserido e legitimado na comunidade. Ao mesmo tempo, a dimensão da comunidade é uma condição essencial para a prática do conhecimento, porque ele só pode ser perpetuado quando transmitido para os novos entrantes da comunidade (GHERARDI, 2000). 
Outro conceito relevante e que tem estreita relação com o de comunidade de prática é o de participação periférica legitimada, que é considerada uma forma específica de engajamento que objetiva socializar os novos membros da comunidade. É periférica porque indica o caminho que um novo aprendiz - um gerente, por exemplo - deve seguir para ser legitimado como integrante da comunidade. Esse conceito ratifica que a aprendizagem é social e não simplesmente cognitiva (GHERADI, NICOLINI, ODELLA, I998b). De acordo com Elkjaer (200I, p. I08), a participação periférica legitimada

[....] chama a atenção para o fato de que os aprendizes estão, inevitavelmente, participando em comunidades de prática - em contextos interagentes. A fim de que os novatos possam acumular conhecimento, adquirir habilidade e/ou aprender alguma forma de profissão ou tarefa num ambiente organizacional, eles devem participar integralmente nas chamadas práticas socioculturais de uma comunidade profissional [...] encarar a aprendizagem como uma parte integral e inseparável da prática social implica que aprender uma habilidade provém de fato do engajamento no processo de desempenho. Os conceitos de significado, compreensão e aprendizagem são todos definidos em relação aos contextos acionais, e não, meramente, em relação à mente.

A noção de participação periférica legitimada delineia um caminho a ser seguido para conseguir aceitação dos demais integrantes da comunidade. É um modo específico de engajamento, pelo qual os novos membros da comunidade socializam e aprendem, assim como pelo qual a comunidade se perpetua. Essa trajetória depende de um currículo situado, que compreende um padrão de oportunidades de aprendizagem que está disponível para os novatos ao ingressarem em uma comunidade específica de uma organização.

A noção de currículo situado deriva do conceito de currículo de aprendizagem proposto por Lave e Wenger (I99I). São duas maneiras de vislumbrar o processo de aprendizagem. Enquanto o currículo de aprendizagem enfatiza as oportunidades de aprendizagem relacionadas a uma ocupação específica, o currículo situado envolve um grupo de atividades que governa o processo de tornar-se um membro; é característico das práticas de uma comunidade e não pode ser considerado dela separado; está enraizado nos hábitos gerais e nas tradições e é sustentado e tacitamente transmitido de uma geração para outra, incorporando modificações no sistema de práticas (GHERADI, NICOLINI, ODELLA, I998b).

Um estudo realizado pelas autoras com gerentes da construção civil, cuja natureza da atividade envolve o relacionamento, a coordenação, a negociação e a resolução de problemas, revelou que, para tornar-se um gerente e conquistar a aceitação e a confiança dos outros na indústria (pedreiros, subcontratados, enge- 
nheiros etc.), um novato deve ser bem-sucedido, mostrar proficiência e tornar-se independente progressivamente na execução de um certo número de práticas de trabalho específicas.

O gerente vai ampliando seu escopo da atividade gerencial, e isso implica desenvolver atividades mais complexas. As tarefas associadas à aprendizagem estão intimamente relacionadas ao tipo de atividade desenvolvida, e isso também significa que o aumento no nível de responsabilidade e de complexidade tem implicações no desenvolvimento de competências gerenciais e também decorre de um processo de legitimação, que ocorre a partir do momento em que os relacionamentos formais e informais estabelecidos o levam a ser reconhecido como aprendiz e como gerente.

Existe uma forte relação no currículo situado do gerente com o desenvolvimento de competências a partir do momento em que ele é engajado em uma série de atividades e passa a ser um participante ativo de todo o processo. A posição do gerente vai mudando à medida que ele vai obtendo maiores informações da empresa, ampliando o nível de conhecimento da organização, dos processos, dos relacionamentos internos e externos. Essa perspectiva de aprendizagem está intimamente relacionada à noção de competências estabelecida por Zarifian (200I, p. 72) quando associa a competência a "um entendimento prático de uma situação que se apóia nos conhecimentos adquiridos e os transforma na medida em que aumenta a diversidade das situações".

Essas considerações indicam que a aprendizagem gerencial também ocorre no contexto da prática, e o gerenciamento da aprendizagem indica a existência de um vínculo entre contexto social, experiência e aprendizagem.

\section{CONTEXTO SOCIAL, EXPERIÊNCIA E APRENDIZAGEM}

$\mathrm{O}$ ato de gerenciar um grupo de pessoas ou uma organização não ocorre de forma isolada. Esse ato social sofre a influência de uma série de agentes, tais como subordinados, pares, clientes, fornecedores, representantes da comunidade, familiares, entre outros, que atuam em diferentes perspectivas. A habilidade para compreendê-las, para utilizar o conhecimento do trabalho, a linguagem e o poder para facilitar o ato de ensinar, é uma função da totalidade de cada experiência vivida do profissional (MCLEOD, 200I).

A aprendizagem gerencial, numa perspectiva mais ampla, sofre a influência de vários contextos (biográfico, histórico, cultural, estrutural), o que demonstra que as experiências vividas pelos gerentes podem contribuir não apenas para enriquecer suas competências profissionais, como também a sua vida pessoal. 
Clark e Clark (I996) discutem como os líderes aprendem com a experiência. Os autores destacam que as experiências de vida podem afetar o desenvolvimento das pessoas, e que recordar de fatos que ocorreram nas suas vidas pode fornecer insights para bons métodos de ser pai ou mãe, de ensinar e talvez liderar:

As origens das mais altas aspirações, de um forte senso de dever e de valores que guiam as decisões podem freqüentemente ser atribuídas às influências dos pais, dos avós e outros modelos (CLARK; CLARK, 1996, p. I53).

Em um estudo realizado com dirigentes de uma pequena empresa, Silva e Rebelo (2006) constataram que a gênese da aprendizagem dos gerentes estudados está ligada à experiência vivida da pessoa, cuja base está na família, mas também ocorre por intermédio das relações em outros contextos e grupos sociais, como a escola e o mundo do trabalho. É um processo dinâmico, multifacetado, reflexivo e transformador. No Quadro 3, são apresentados alguns fatores subjacentes às experiências vividas pelos gerentes que influenciaram sua aprendizagem.

\section{QUADRO 3}

FATORES SUBJACENTES A EXPERIÊNCIA VIVIDA QUE INFLUENCIARAM NA APRENDIZAGEM DOS GERENTES

\begin{tabular}{|c|c|}
\hline DIMENSÃO & FATORES DE INFLUÊNCIA NA APRENDIZAGEM DOS GERENTES \\
\hline FAMÍLIA & $\begin{array}{l}\text { Perseverança, determinação, dignidade, caráter, responsabilidade, vontade } \\
\text { de vencer, apoio, solidez nas relações familiares. }\end{array}$ \\
\hline ESCOLA & Apoio, trauma pessoal, convivência, decepções, perdas. \\
\hline COMUNIDADE & $\begin{array}{l}\text { Liderança, relacionamento interpessoal, convivência, comunicação, } \\
\text { coordenação de trabalho em equipe. }\end{array}$ \\
\hline $\begin{array}{l}\text { VIDA DE } \\
\text { EMPREGADO }\end{array}$ & $\begin{array}{l}\text { Incompatibilidade de valores, observação, proatividade, dedicação, resolução } \\
\text { de problemas, reflexão na ação, valorização da imagem pessoal, liderança, } \\
\text { argumentação, sofrimento, determinação, valorização das pessoas, solidão, } \\
\text { humildade. }\end{array}$ \\
\hline $\begin{array}{l}\text { VIDA DE } \\
\text { GERENTE }\end{array}$ & $\begin{array}{l}\text { Responsabilidade, visão sistêmica do negócio, perseverança, coragem, } \\
\text { proatividade, inovação, divisão de papéis, gerenciamento de si próprio, } \\
\text { respeito e transparência nas ações, ética, participação, gestão do tempo, } \\
\text { relação entre vida pessoal e trabalho. }\end{array}$ \\
\hline
\end{tabular}


Esses resultados indicam como o contexto social pode contribuir para a aprendizagem de gerentes. A experiência social é considerada um dos eixos formadores de uma competência (LE BOTERF, 2003), e isso indica que os gerentes precisam compreender o papel que os vários eventos vivenciados ao longo de suas vidas exercem em sua prática gerencial.

Cornbleth (I998 apud MCLEOD, 200I) destaca que cada interação do profissional é uma função do contexto biográfico - não apenas do dele, mas daqueles que interagem com ele. O contexto biográfico representa cada personalidade formada em circunstâncias sociais que incluem suas experiências, suas interações com outros indivíduos, grupos, instituições, e o ambiente tanto físico como humano, natural e artificial.

Numa perspectiva sociológica, Jarvis (I992 apud MERRIAN; CAFARELLA, I99I, p. 63) situa a aprendizagem na interface da biografia das pessoas e do meio sociocultural em que elas vivem, e é nessa interseção que as experiências ocorrem. O autor também faz um link entre aprendizagem e desenvolvimento. A aprendizagem das experiências do dia-a-dia é um processo que ocorre todo o tempo. As pessoas se desenvolvem e amadurecem mediante essas experiências.

Após um estudo realizado com gerentes no contexto organizacional, Tamkin e Barber (I998) constataram que esses profissionais aprenderam várias coisas em suas experiências que estão associadas a conhecimentos, habilidades técnicas e gerenciais, aumento da compreensão de como funciona a empresa, aumento da compreensão do impacto das suas ações nos outros e em si mesmos. Na pesquisa, ficou claro que o que o gerente aprende é fortemente influenciado pelo como ele aprende.

Pode-se afirmar ainda que a aprendizagem de gerentes no trabalho é fortemente influenciada pelas experiências vividas por eles ao longo de suas vidas. A maneira como os gerentes viveram suas experiências influenciou o que eles aprenderam ao longo de suas vidas. As experiências fora do ambiente de trabalho são ricas em oportunidades de aprendizagem. Algumas vezes, essas oportunidades vêm sem avisar, como em um sofrimento. Freqüentemente, podem-se escolher experiências que constroem habilidades específicas de liderança (RUDERMAN; OLHOTT, 2000).

Além dessas considerações, Ruderman e Olhott (2000) ainda destacam que a aprendizagem no trabalho ocorre quando a oportunidade e a motivação para aprender interagem e criam a necessidade para o desenvolvimento. Nesse sentido, compreender a aprendizagem sob uma perspectiva da ação merece destaque e será abordada na próxima seção. 


\section{A APRENDIZAGEM DE GERENTES EM AÇ $\tilde{A} \mathbf{O}$}

A aprendizagem de gerentes, numa perspectiva prática, está centrada no desenvolvimento de um processo de aprendizagem focado na ação no ambiente profissional. Como as empresas podem criar o ambiente necessário para fomentar a aprendizagem? Quais são as premissas de um programa de aprendizagem focado na ação?

Algumas empresas vêm desenvolvendo programas centrados na aprendizagem na ação que procuram incentivar a reflexão dos gerentes e de todos os agentes envolvidos nos processos de gestão empresarial. Segundo Marsick (I990), a aprendizagem na ação foi desenvolvida por Revans. A proposta de Revans para a aprendizagem na ação tinha como objetivo desenvolver um sistema para o desenvolvimento da administração.

Segundo Marsick (I990), um dos pressupostos básicos dessa teoria é que os gerentes devem refletir sobre suas experiências com os outros em projetos de aprendizagem para extrair uma teoria personalística da administração. A aprendizagem na ação ajuda no desenvolvimento de habilidades de administração geral e no pensamento estratégico quando os executivos necessitam exercer a liderança na resolução de problemas complexos que ainda não têm solução.

A emergência da aprendizagem na ação como uma abordagem popular foi intensificada na década de I990, com dois objetivos principais: produzir soluções para os problemas organizacionais e desenvolver o talento da administração. A aprendizagem na ação é uma abordagem baseada na experiência, para pessoas que usam o trabalho em problemas significativos como uma maneira de aprender (YORKS, 2000).

A aprendizagem na ação deve ser usada quando a organização lida com problemas da vida real que não têm soluções claras e pode ser descrita como um processo social de gerentes e trabalhadores que atuam em conjunto para revisar, interpretar suas experiências e compreender os processos que os têm levado a solucionar problemas. Para ser efetivo, um programa centrado na aprendizagem na ação deve proporcionar o crescimento pessoal e organizacional (DE LOO; VERSTEGEN, 200I).

Marsick (I990, p. 60) afirma que, apesar dos obstáculos, muitas empresas estão utilizando a aprendizagem na ação de alguma forma, pois reconhecem que: 
a) os executivos devem descobrir muitas respostas no mundo de hoje por meio do exame de suas próprias experiências;

b) as empresas não podem sobreviver em um mundo repleto de desafios sem uma nova forma de desenvolver e manter uma equipe, que a aprendizagem na ação efetivamente adota;

c) a aprendizagem na ação é mais eficiente do que a aprendizagem isolada porque abrange um tipo de grupo guiado, que facilita a tentativa e o erro.

O que torna a aprendizagem na ação única é o uso de problemas reais e dilemas. Tais problemas são estruturados como questões que são reestruturadas por meio de ciclos de ação e reflexão (YORKS, 2000). É um processo que envolve a busca do conhecimento em relação ao trabalho, mas também o autoconhecimento, por meio das atividades realizadas na organização.

O processo de conhecer-na-ação de um profissional tem suas raízes no contexto social e institucionalmente estruturado do qual compartilha uma comunidade de profissionais. Conhecer-na-prática é exercitado nos ambientes institucionais particulares da profissão, organizados em termos de suas unidades de atividade características, seus tipos familiares de situações práticas e limitado ou facilitado por seu corpo comum de conhecimento profissional e de seu sistema apreciativo (SCHON, 2000, p. 36).

O sistema apreciativo abrange um sistema de valores, preferências e normas que auxilia as pessoas a compreenderem situações práticas, auxiliando na formulação de objetivos e diretrizes para a ação, determinando o que constitui uma conduta social aceitável (SCHON, 2000).

A aprendizagem ocorre por meio da prática, e sua meta é descobrir o que fazer, quando fazer, como fazer, usando rotinas e artefatos; é um processo que ocorre em grupo (entre e por meio de outras pessoas) (GHERARDI, NICOLINI; ODELLA, I998b). Essa perspectiva destaca o papel do grupo no processo de aprendizagem gerencial, mas a aprendizagem inicia-se no nível individual, e, como adultos, os gerentes devem assumir o papel de direcionadores do próprio processo de aprendizagem.

A aprendizagem autodirecionada "é uma forma de estudo na qual os aprendizes têm uma responsabilidade primária por planejamento, realização e avaliação de suas próprias experiências” (MERRIAN; CAFARELLA, I99I, p. 4I). Esse tipo de aprendizagem ocorre dentro e fora dos programas de aprendizagem, o que a torna parte integrante da vida adulta. 
Os aprendizes efetivos, autodirigidos, têm a iniciativa na descoberta do que precisam aprender. São pessoas conscientes das suas necessidades e têm senso de orientação para definir a direção da aprendizagem: "A aprendizagem autodirecionada requer que o indivíduo seja o educador e o aprendiz ao mesmo tempo" (DECHANT, I990, p. 42).

Aprender por si próprio não quer dizer aprender sozinho. No ambiente empresarial, por exemplo, os gerentes podem aprender com seus pares e subordinados. É um espaço social rico em oportunidades de aprendizagem, mas também é um terreno que pode apresentar várias barreiras organizacionais, grupais e individuais à aprendizagem.

O controle, a liberdade e a flexibilidade são os principais fatores motivadores para o engajamento na aprendizagem autodirecionada (MERRIAN; CAFARELLA, I99I, p. 44).

Um estudo realizado com 2I gerentes seniores revelou que o foco dos esforços da aprendizagem autodirecionada foi em aprender a fazer o que fosse necessário para informar seus julgamentos e guiar suas decisões na execução de suas tarefas. Nesse processo, eles não só adquiriam novos conhecimentos e habilidades, mas serviam como principais condutores para direcionar o novo conhecimento (DECHANT, I990). O estudo também revelou que a aprendizagem autodirecionada, como praticada pelos gerentes, ocorreu de duas formas.

a) Técnicas para identificar metas, selecionar e perseguir as experiências de aprendizagem e avaliar o progresso.

b) Mudanças na consciência na qual o conhecimento é considerado contextual e relativo. Valores pessoais e crenças são vistos como culturalmente relacionados, e o resultado altera a perspectiva usada para determinar decisões e ações que produzem mudança pessoal e organizacional.

Vale ressaltar que esse processo depende de uma série de variáveis, tais como: as motivações do aprendiz, as circunstâncias nas quais ele descobre a si, sua habilidade em conduzir o processo de aprendizagem, o conhecimento prévio e a experiência com o conteúdo que será aprendido (MERRIAN; CAFARELLA, I99I).

Os profissionais que atuam no desenvolvimento de gerentes devem passar a incorporar essas variáveis na elaboração, no planejamento, na implantação e na avaliação de programas direcionados para a aprendizagem gerencial. 


\section{CONSIDERAÇÕES FINAIS}

A aprendizagem gerencial é uma abordagem que procura integrar a educação, a experiência e o contexto da ação gerencial. Suas bases epistemológicas estão enraizadas na psicologia, na educação, na sociologia e na teoria das organizações, e integra um campo dos estudos organizacionais. Seu objetivo é a compreensão dos vínculos entre o escopo e os processos de aprendizagem, focalizando a relação entre a educação, o desenvolvimento e a prática gerencial.

A análise do processo de aprendizagem de gerentes, com base em uma abordagem multidimensional, indica que existem categorias de aprendizagem que envolvem não apenas a dimensão técnica associada ao conhecimento, mas também a compreensão do contexto da ação profissional, que contribui para o desenvolvimento de habilidades e também suscita a mudança nas perspectivas de significado, ampliando o reconhecimento de seus comportamentos e ajudando no seu autodesenvolvimento.

Com base no que foi abordado neste artigo, percebe-se a influência do contexto social na aprendizagem de gerentes, uma vez que existem fatores contextuais que interferem em sua prática e contribuem para o desenvolvimento de competências profissionais (ZARIFIAN, 200I; LE BOTERF, 2003) quando ocorre um processo de socialização e de legitimação de seu trabalho pelos demais participantes no contexto da ação, fazendo emergir um profissionalismo reconhecido e legitimado pelos agentes institucionais. É um processo de aprendizagem mediado pelo contexto, pela troca de experiências e pela reflexão na ação (PAULSSON; SUNDIN, 2000; SCHON, I983, 2000; BROWN; DUGUID, 200I). Também está relacionado à reflexividade que ocorre quando o fluxo de experiências é interrompido e o gerente reflete sobre o conhecimento, possibilitando a sua institucionalização. O conhecimento teórico pode ser extraído por meio do conhecimento prático e se transformar em um conhecimento normativo (GHERARDI; NICOLINI, 200I).

A aprendizagem não é apenas um fenômeno individual, mas coletivo, que ocorre em um contexto de participação social. O conhecimento tácito existente em um contexto social é incorporado à prática gerencial a partir do momento em que o gerente é reconhecido como integrante de um grupo social e incorpora esse conhecimento, promovendo uma mudança em suas perspectivas de significado e ampliando o nível de complexidade e responsabilidade do escopo de sua ação gerencial. O contexto torna a aprendizagem situada (LAVE; WENGER, I99I). No processo de aprendizagem, existe um currículo vinculado a oportunidades de aprendizagem relacionadas à formação (educação gerencial). Também existe um currículo situado que abrange um processo de socialização e legitimação de um gerente em um determinado contexto social e que envolve situações de aprendizagem e desenvolvimento de competências vinculadas à ação. 
As experiências vividas fora do contexto profissional, isto é, no contexto da vida pessoal, influenciam o conteúdo (o que) e o processo (como) de aprendizagem gerencial. Essas considerações reforçam o vínculo entre a aprendizagem e o desenvolvimento de competências, numa perspectiva complexa e multidimensional. Le Boterf (2003) destaca a existência de eixos formadores de uma competência que devem ser vislumbrados sob uma perspectiva interacionista da aprendizagem.

Os programas de aprendizagem gerencial devem buscar compatibilizar o desenvolvimento de conhecimentos técnicos vinculados à educação com o desenvolvimento de habilidades gerenciais e a mudança nas perspectivas de significados, por meio da vivência de experiências em situações ricas em aprendizagem, revelando o caráter transformador e emancipatório da aprendizagem.

\section{REFERÊNCIAS}

ARGYRIS, C.; SCHON, D. A. Theory and practice: increasing professional effectiveness. San Francisco: Jossey-Bass Publishers, I974.

BROWN, J. S.; DUGUID, P. Knowledge an organization: a social-practice perspective. Organization Science, v. I2, n. 2, p. I98-213, Mar./Apr. 200I.

CLARK, K. E.; CLARK, M. B. Choosing to lead. 2. ed. Greensboro (NC): Center for Creative Leadership, I996.

CRANTON, P. Understanding and promoting transformative learning: a guide for educators of adults. San Francisco: Jossey-Bass Publishers, I994.

DAFT, R. L. Organizações: teoria e projetos. São Paulo: Thomson Learning, 2003.

DE LOO, I; VERSTEGEN, B. Does action learning lead to organizational growth? Mid Atlantic Journal of Business, v. 37, n. I, p. 55-64, Mar. 200I.

DECHANT, K. Knowing how to learn: the "neglected" management ability. Journal of Management Development, v. 9, n. 4, p. 40-49, I990.

ELKJAER, B. Em busca de uma teoria de aprendizagem social. In: EASTERBY-SMITH, M.; BURGOYNE, J.; ARAUJO, L. Aprendizagem organizacional e organização de aprendizagem: desenvolvimento na teoria e na prática. São Paulo: Atlas, 200I.

FOX, S. Debating management learning: I. Management Learning, v. 25, n. I, I994, p. 83-93.

From management education and development to the study of management learning. In:

BURGOYNE, J.; REYNOLDS, M. (Ed.). Management learning: integrating perspectives in theory and practice. London: Sage, I997. p. 2I-37.

FREIRE, P. Pedagogia do oprimido. I7. ed. Rio de Janeiro: Paz e Terra, I987.

GHERARDI, S. The Organizational Learning of safety in communities of practice. Journal of Management Inquiry, v. 9, n. I, Mar. 2000.

GHERARDI, S.; NICOLINI, D. The sociological foundations of organizational learning. In: DIERKES, M. Handbook of organizational learning and knowledge. New York: Oxford University Press, 200I. p. 35-60. 
GHERARDI, S.; NICOLINI, D.; ODELLA, F. The organization learning of safety in communities of practice. Journal of Management Inquiry, v. 9, n. I, I998a.

Toward a social understanding of how people learn in organizations. Management Learning, v. 29, n. 3, p. 273-297, 1998b.

GIDDENS, A. Novas regras do método sociológico. Rio de Janeiro: Zahar Editores, I978.

GOLD, J. A empresa que aprende baseada no conhecimento. In: CLARKE, T.; MONKHOUSE, E. Repensando a empresa. São Paulo: Pioneira, I995. p. II9-I37.

LAVE, J.; WENGER, E. Situated learning: legitimate peripheral participation. New York: Cambridge University Press, I99I.

LE BOTERF, G. Desenvolvendo a competência dos profissionais. 3. ed. Porto Alegre: Artmed, 2003. LUCENA, E. A. A aprendizagem profissional de gerentes-proprietários do setor de varejo de vestuário de Florianópolis. 200I. I65 p. (Doutorado em Engenharia de Produção)-Centro Tecnológico, Universidade Federal de Santa Catarina, Florianópolis, 200I.

MARSICK, V. Experience-based learning: executive learning outside the classroom. Journal of Management Development, v. 9, n. 4, p. 50-60, I990.

MCLEOD, H. Teacher's Working Knowledge: The Value of Lived Experience. Ultibase articles, Melbourne, p. I-IO, Nov. 200I.

MERRIAN, S.; CAFFARELLA, R. Learning in adulthood: a comprehensive guide. San Francisco: Jossey-Bass, I99I.

NICOLINI, D.; MEZNAR, M. B. The social constrution of organizational learning: conceptual and pratical issue in the field. Human Relations, v. 48, n. 7, p. 729-745, I995.

PAULSSON, K.; SUNDIN, L. Learning at work - a combination of experience-based learning and theoretical education. Behavior \& Information Technology, v. I9, n. 3, p. I8I-I88, 2000.

RUDERMAN, M. N.; OHLOTT, P. L. Learning from life: turning life's lessons into leadership experience. North Carolina: Center for creative leadership, 2000.

SCHON, D. A. The reflective practitioner: how professionals think in action. USA: Basic Books, I983. Educando o profissional reflexivo: um novo design para o ensino e a aprendizagem. Porto Alegre: Artes Médicas Sul, 2000.

SENGE, P. (Org.). A dança das mudanças. Rio de Janeiro: Campus, I999.

SILVA, A. B.; REBELO, L. M. B. A gênese da aprendizagem no contexto social: a experiência vivida de gerentes. Revista Alcance, Itajaí, v. I3, n. I, p. 9-27, jan./abr. 2006.

SILVA, M. A. da; CUNHA, C. J. C. A.; POSSAMAI, F. O que os professores aprendem para dirigir unidades universitárias: o caso da UFSC. In: ENCONTRO DA ANPAD, 25., 200I, Campinas. Anais... Campinas, 200I. CD-ROM.

STARKEY, K. What can we learn from the learning organization? Human Relations, v. 5I, n. 4, p. 53I-546, I998.

STEWART, T. A. Capital intelectual: a nova vantagem competitiva das empresas. Rio de Janeiro: Campus, I998.

TAMKIN, P.; BARBER, L. Learning to manage. England: Ikon Office Solutions, I998.

TAYLOR, E. W. The theory and practice of transformative learning: a critial review. Information Series, n. 374, I998.

YORKS, L. The emergence of action learning. Training \& Development, Jan. 2000.

YUKL, Gary. Leadership in organizations. 4. ed. New York: Prentice Hall, I998.

ZARIFIAN, P. Objetivo competência. São Paulo: Atlas, 200I. 